\title{
HALLETT'S METHOD OF BREEDING AND 'THE PURE LINE THEORY
}

\author{
J. Arthur Harr!s
}

Cold Spring Harbor, Long Island, Neto York

Before the symposium on the "Genotype or Pure Line Theory of Johannsen," Professor Webber urged the importance of certainty concerning the validity of scientific theories before they are unqualifiedly commended as rules of conduct for the practical man. Selection has been the key of the breeder's success. In his practical operations it is impossible for him to know whether he is selecting "fluctuations" or "mutations," "modifications" or "biotypes." Much harm may be done, Professor Webber insisted, by assuring the practical breeder (on the grounds of an inadequately supported theory) that he may give up continued selection for a mere process of isolation.

In this connection, it seems worth while to lay before breeders a few paragraphs from the noted cerealist Hallett. His experience while pertinent to, and extensively discussed in connection with, modern theories does not seem to me to have always been clearly set forth.

From his main paper, ${ }^{b}$ we learn certain facts which indicate clearly his belief that selection within the pure line can effect an improvement.

After discussing, among other things, methods of planting to allow for full individual development ${ }^{\circ}$ he continues:

Yet the minutest characteristics of a plant of wheat will be reproduced in its descendants; so much so, that we can not only perpetuate the advantages presented to us in an individual ear, but by the accumulation of selection, make further advances in any desired direction. . . . . To me it has always appeared that, while offering an earnest of what a better system would effect, the mode in which the best varieties of our cereals have been raised (that is starting with accidentally fine ears, and simply keeping the produce unmixed without any further selection) is a very imperfect one, and that its attainments are perhaps of less value than the earnest which it offers of future

- Held under the auspices of the American Soclety of Naturalists at Ithaca, December, 1910. For papers sece American Naturaliat, 1011.

b Hallett, F. P., "On 'Pedigree' in Wheat as a Mreans of Increasing the Crop," Journ. Agr. Soc. 22: 371-381, plate. 1861. In 1860, Hallet formulated seven lawB oncerning the improvement of cereals. These may be read in Sect. Trans., Rop. Brit. Aw. (Fretar) 39: 113, 1870. or In Jorrn. Bot. 7: $293,1800$.

- The poesibility of an accumulative effect of the espectally favorable conditlons under which Hn]lett crow his podicree plants must, of course, be taken into socount. There is, howover, little reason for attributing to this phystologteal factor a role at all commensurate with that of seloction.

d The Italice are as in the ortelinal. 
success under a more complete system, for such beginning (and ending, so far as selection is concerned) with an accidentally fine ear, is a very different thing from starting annually with one of a known lineage.

\section{Hallett's method of selection is as follows:}

A grain produces a "stool" consisting of many ears. I plant the grains from these ears in such a manner that each ear occupies a row by itself. . . . At harvest, after the most careful study and comparison of the stools from all these grains, I select the finest one, which I accept as proof that its parent grain was the best of all, under the peculiar circumstances of that season. This process is repeated annually, starting each year with the proved best grain, although the verification of this superiority is not obtained until the following harvest.

During these investigations no single circumstance has struck me as more forcibly illustrating the necessity of repeated selection than the fact, that of the grains in the same ear one is found greatly to excel all the others in vital power.

Two things are clear from this quotation. First, Hallett used fifty years ago the "ear to row" test so often emphasized as a modern method. Second, his method of selection in wheat, a generally selffertilized plant, was essentially a method of improvement by selection within the pure line!

Again, in another place, ${ }^{\circ}$ Hallett leaves no doubt as to his position regarding selection.

In the case of the potato, . . . . I have also applied my system, starting every year with a single tuber, the best of the year (proved to have been so by its having been found to produce the best plant), for now fourteen years. My main object has been absolute freedom from disease, and these potatoes are now descended from a line of single tubers, each the best plant of the year, and absolutely healthy; and concurrently with the endeavor to wipe out all hereditary tendency to disease, $I$ have always kept in full view the point of increasing productiveness. The result may be thus shortly stated. Dividing the first twelve years into three periods, the average number of tubers upon the annual best plant selected was, for the first period of four years, 16; for the second period of four years, 19; for the last period of four years, 27, or nearly double the number produced during the first series of four years. And if, as I might very fairly have done, I had confined the firat period to the first three years (instead of four), the last period would have ahown an average of 27 tubers against 13 in the first period, or more than double. Here, exactly, as with the number of grains in the ear of the cereals, we reach in the last period of a long series of years, a standard al together higher than in the first years of the series, and this no matter how we divided it into "periods." In the latter "periods" of a series of years the results vary according to season and circumstances; but (except in a case of diaster) in no year of the last year of a series do they drop back to the standard of earlier years!

- Hallett, F. P., “Food Plant Improvement," Nature 26: 91-94. 1882. 
In quoting this paragraph I am quite aware that geneticists are wont to be sceptical of the opinions of the men who have worked primarily for practical results. When there is not a mass of quantitative evidence, scepticism is quite justified. On the other hand, the opinion of a man who says he has actually done a thing on a large and practical scale is worth quite as serious consideration as that of the man who on limited experimental evidence says it cannot be done. But laying this question of the critical value of Hallett's opinions aside, one must admit that if a man's results are to be cited in evidence at all they should be correctly set forth. I believe some serious misunderstandings of Hallett's view have followed erroneous descriptions of his work. These can perhaps be best corrected by fair quotations from his own pen.

\title{
THE DOMINANCE OF RECESSIVES
}

\author{
A. Jay Garrison \\ Edgewater, Colorado.
}

If dominance is an absolute principle and its relation to recessives is immutable, our subject is an absurd contradiction of terms, but these suppositions are in no respect true. Especially within the zone of variety, dominance is an extremely variable quantity. Genetic factors operate from radiating centers which may be readily shifted by the potency of either side in any given mating, or by a variety of environmental conditions.

Although we then knew nothing of the Mendelian terminology, our attention was first attracted to the principle of dominance in the autumn of 1867 , while herding cattle in southern Iowa. In covering portions of four counties we encountered large native orchards of Americana plums. Our previous experience in nursery and horticultural work led us to examine these orchards with absorbing interest. We everywhere found three colors-red, yellow, and mottled or blends. While large groups of the same color were generally found in close proximity, occasionally a specimen of distinct color and variety bad maintained its individuality. When examined at blooming time it was found that there was an interim of several days between the time of blooming of the individual tree and the adjacent group.

We have at times been greatly amused at the labored explanations of some scientists who portray nature as adorning herself in a gay attire of many colors and performing all manner of gyrations, $a$ la 